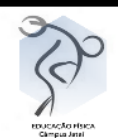

\title{
Efeito ergogênico da cafeína sobre a fadiga e a dor durante o exercício: uma revisão sistemática
}

\author{
Marla Aparecida Silva ${ }^{1}$ \\ Priscila Carneiro Valim Rogatto ${ }^{2}$ \\ Gustavo Puggina Rogatto ${ }^{3}$ \\ Maria Claudia Bernardes Spexoto ${ }^{4}$ \\ Chaysther de Andrade Lopes ${ }^{5}$ \\ Rênica Alves de Morais Rocha ${ }^{6}$ \\ David Michel de Oliveira ${ }^{7}$
}

Resumo: A cafeína é uma substância ergogênica utilizada para aprimorar o rendimento esportivo, sendo seus efeitos central e periféricos, podendo interferir na percepção de dor durante esforços exaustivos. No âmbito esportivo a fadiga é um fator limitante do desempenho e para isto atletas e treinadores têm investido incansavelmente em recurso avançados de interesse no ramo científico para atenuar esta fadiga visando melhor performance no esporte. Objetivo: o presente estudo teve como objetivo investigar o efeito ergogênico da cafeína sobre a fadiga e a dor durante o exercício. Método: para isto foi conduzida uma revisão sistemática sobre seus efeitos, utilizando as Bases de Dados, Scielo, Bireme e Pubmed. Resultados: foram encontrados diferentes trabalhos que demonstraram a eficácia da cafeína como um potente ergogênico em diferentes esportes. Conclusão: encontramos também que a cafeína atua em diferentes aspectos agindo de forma eficaz nos sistemas nervoso central (SNC) e cardiorrespiratório. Atuando sobre o limiar de esforço e dor e retardando a fadiga muscular e assim melhorando o desempenho do atleta.

Palavras - chave: Revisão sistemática. Cafeína. Dor. Fadiga muscular.

\section{Caffeine ergogenic effect on fatigue and pain during the exercise: a systematic review}

\footnotetext{
Abstract: Caffeine is an ergogenic substance used to improve sports performance, with its central and peripheral effects, which may interfere with the perception of pain during exhausting efforts. In sports, fatigue is a limiting factor of performance and for this, athletes and coaches have been relentlessly investing in advanced resources of scientific interest to alleviate this fatigue aiming at better

${ }^{1}$ Licenciada em Educação Física pela Universidade Federal de Lavras. E-mail: marla-arena@ @otmail.com

2 Docente do curso de Educação Física da Universidade Federal de Lavras. E-mail: valimrogatto@ def.ufla.br

${ }^{3}$ Docente do curso de Educação Física da Universidade Federal de Lavras. E-mail: rogatto@ def.ufla.br

${ }^{4}$ Docente do curso de nutrição da Universidade Federal da Grande Dourados (UFGD). E-mail: mariaspexoto@ufgd.edu.br

${ }^{5}$ Docente do curso de Educação Física da Universidade Federal de Jataí (UFJ). E-mail: Chaystherlopes@ hotmail.com

${ }^{6}$ Mestra do Programa de Ciências aplicadas a Saúde da Universidade Federal de Goiás (UFG/REJ)

E-mail: renicamorais@hotmail.com

${ }^{7}$ Docente do curso de Educação Física da Universidade Federal de Jataí (UFJ). E-mail: profdoliveira@gmail.com
} 




performance in the sport. Objective: The present study aimed to investigate the caffeine ergogenic effect on fatigue and pain during the exercise. Method: For this, a systematic review about its effects was conducted using the databases, Scielo, Bireme and Pubmed. Results: Different studies were found that demonstrated the effectiveness of caffeine as an ergogenic potent in different sports. Conclusion: We also found that caffeine operate in different ways acting effectively in the central nervous and cardiorespiratory systems, acting on the threshold of effort and pain and slowing muscle fatigue and thus improving athlete performance.

Keywords: Systematic review. Caffeine. Pain. Muscle fatigue.

\section{INTRODUÇÃO}

Atualmente está cada vez mais perceptível à importância da prática de exercícios físicos regulares, e com o passar dos anos, percebe-se a necessidade de preparar o corpo de forma adequada para possibilitar uma qualidade de vida (QV), assim incorporando um programa de exercício físico. É importante ressaltar que para um programa de exercício tornar-se adequado, são necessários aspectos importantes a serem considerados como: tipo de exercício, intensidade, duração, frequência bem como a progressão destes componentes (MONTEIRO, 2000). Além da população geral, que é considerada praticante de exercício físico existem também atletas, que em diferentes dimensões estão, constantemente, em busca de melhores resultados, o que em muitas vezes o treinamento adequado não é suficiente para um bom rendimento, por esta razão a busca por inúmeros recursos ergogênicos está em evidência.

Ergogênico vem do grego, onde "ergo" significa trabalho e "gen" produção, sendo assim, defini-se como o aumento da capacidade de trabalho corporal. (MICHAELIS, 2015)

A cafeína é uma das substâncias mais utilizadas no mundo, ela está presente em diversos alimentos populares e, por isso, é de fácil acesso.

É um produto utilizado em diferentes condições como por exemplo na prevenção de patologias como Diabetes tipo 2 (DM2), depressão, insônia entre outros.

A cafeína tem mostrado efeito ergogênico, na medida em que a sua ingestão apresenta resultados na redução da dor muscular, aumentando o consumo de oxigênio durante o exercício e assim retardando a fadiga, principalmente pelo seu efeito lipolítico, que promove maior consumo de gordura, poupando o glicogênio muscular (HUNTER et al., 2002, MOTL et al., 2006, WOOLF et al., 2008, GRAHAM et al., 2008). 


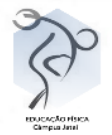

O consumo de cafeína é relativamente seguro, e não são conhecidos efeitos negativos na performance física, nem tão pouco causa desidratação significativa ou um desequilíbrio eletrolítico durante o exercício (SOARES e FONSECA, 2004).

Ainda que nenhum recurso ergogênico seja capaz de parar o processo da fadiga muscular, por completo, existem evidências de que o consumo regular dessa substância pode minimizar os efeitos fisiológicos no SNC.

Esse tipo de recurso tem atenuado níveis de fadiga muscular e a percepção de dor durante o exercício físico, portanto sendo capaz de melhorar o rendimento esportivo. No entanto, ainda não se tem muito clara qual seria a melhor combinação desse recurso ergogênico e se este por sua vez poderia ser utilizado para pessoas não treinadas, pois $100 \%$ dos estudos encontrados na literatura foram feitos com atletas e não com pessoas sedentárias.

Assim, portanto pretendemos verificar a atuação da cafeína e seus benefícios sobre a fadiga e na percepção de dor durante a prática de exercício físico prolongado.

\section{CAFEÍNA}

A cafeína é uma das substâncias mais consumidas mundialmente de acordo com o estudo de (ESCOHOTADO,1999).

Ela é conhecida quimicamente por 1,3,7,trimetilxantina, o que nos chama atenção devido que o grupo das xantinas são utilizadas para finalidades terapêuticas e farmacológicas as quais tem um potencial de ação diretamente no sistema nervoso central SNC (ALTIMARI et al, 2006; SILVA, 2003)

A cafeína é consumida de diversas formas, pois esta contida em frutas como o guaraná e cacau, folhas de chás, em grãos como o próprio café e em medicamentos analgésicos, relaxantes musculares e remédios para enxaqueca (GRAHAM, 2001).

Em termos neurofisiológicos, a cafeína age como estimulante bloqueando receptores de adenosina no cérebro com isto existe também um aumento nas atividades do SNC e isto leva com que os efeitos calmantes sejam aparentes (SNYDER; SKLAR, 1984).

Portanto a cafeína produz efeitos psicoestimulantes, atuando positivamente sobre o humor e, especificamente, no desempenho psicomotor (DUNCAN; OXFORD, 2011). 
Como a cafeína bloqueia os efeitos da adenosina isto faz com que a força contrátil no músculo esquelético seja potencializada, com isto existe um aumento no estado de alerta dessa forma uma diminuição da sensação de fadiga, permitindo um aumento do desempenho esportivo. (PLASKET e CAFARELLI, 2001; PEREIRA et al,2010; FERREIRA,GUERRA E GUERRA,2006)

Paluska (2003)afirma que a cafeína promove melhora da concentração, diminui a fadiga e aumenta o estado de alerta, e seu consumo habitual não afeta suas características ergogênicas. Porém, a uso crônico causa dependência, igualmente se houver uma interrupção do uso isto pode provocar mudança de humor, cefaleia e fadiga no individuo.

Acredita-se que devido às pessoas reconhecerem a cafeína como um estimulante natural, barato e de fácil acesso exista um alto consumo de tal substancia, assim adentrando para o meio esportivo a utilização da cafeína como recurso ergogênico para melhora do desempenho físico por grandes atletas (DANTAS 2003).

Após a ingestão da cafeína muitos atletas sentem-se estimulados e com isto muitos acreditam poder realizar um esforço maior antes de alcançar a fadiga muscular, permitindo maior rendimento no esporte. Isto esta relacionado diretamente com o efeito estimulante que a cafeína produz no SNC. (CLARK, 2006).

Altimari et al(2000) verificaram que a utilização da cafeína durante exercícios físicos de media e longa duração, poderá gerar uma melhoria na ação metabólica dos sistemas energéticos e assim fazer com que exista uma melhoria no desempenho físico, embora não se saiba de que forma o mecanismo de ação responsável pelo aumento da força muscular haja.

Kalmar e Cafarelli (2004) observaram que após a ingestão de cafeína em exercícios de ciclismo supra-Maximo houve uma redução significante na fadiga e que também a fadiga central foi consideravelmente reduzida.

A utilização da cafeína está ligada a diversas situações, uma delas para alivio da dor cabeça e melhora no humor, em alguns estudos existe a citação em que a utilização da cafeína causou uma diminuição na cefaleia dos indivíduos.

\subsection{A Cafeína como recurso Ergogênico}


Os efeitos da cafeína ainda não são conhecidos em sua totalidade, mas sabemos que é um potente ergogênico, pois por anos estava na lista de substancias proibidas assim considerada doping pelo Comitê Olímpico Internacional (BRAGA E ALVES, 2000).

Após a remoção da cafeína da lista de substâncias proibidas pela agência mundial anti-doping ( WADA,2015) seu consumo ganhou destaque.

Del Coso et al.(2011),observaram que três em cada quatro atletas fazem o uso da cafeína durante os treinos pré-competitivos e nos próprios eventos ,devido a cafeína ser uma substancia de fácil acesso e por estes atletas acreditarem em seu potente efeito em sua performance.

Desse modo, a cafeína tomou força devido o livre comercio e fácil acesso aos usuários, sendo utilizada de maneira convencional por inúmeros atletas devido aos benefícios durante os exercícios físicos em diferentes modalidades e principalmente na melhora do desempenho durante as provas de longa duração.

É notável que a cafeína tem sido alvo de inúmeros pesquisadores e atletas, podemos fazer referência ao estudo de Paiva et al (1985), que já estavam de olho no benefícios que a cafeína poderia trazer para seus usuários.

\subsection{Os efeitos da Cafeína e o comportamento humano}

$\mathrm{O}$ indivíduo sente durante alguns minutos que são mais fortes e mais competitivos, acreditando poder realizar uma atividade física e mental por um tempo mais prolongado antes que se inicie a fadiga (BERTAZZONI, 2007).

Podemos descrever esses efeitos como o aumento da capacidade de alerta e redução da fadiga e assim melhorando a performance durante diversos esportes.

Por décadas o efeito da cafeína sobre o comportamento humano vem sendo estudado, esses efeitos podem ser descritos, redução da fadiga e aumento do estado de alerta (DE MARIA E MOREIRA, 2007).

A cafeína afeta quase todos os sistemas do organismo, mas grande parte afetada é o SNC. Seus efeitos estão ligados diretamente com a dosagem consumida se são altas o indivíduo pode ficar desidratado, e causar irritabilidade, já se são baixas dosagens a cafeína 


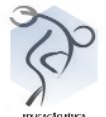

pode provocar alivio da fadiga, aumento do metabolismo diminuição do sono e aumento do estado de alerta (BRAGA E ALVES,2000).

Os efeitos ergogênicos da cafeína durante o exercício físico estão relacionados principalmente a um aumento na liberação de catecolaminas e mobilização de ácidos graxos, consequentemente resultando em uma diminuída utilização do glicogênio intramuscular como fonte de energia. Esses mecanismos fisiológicos de ação da cafeína poderiam retardar o início da fadiga muscular periférica, contribuindo para um aumento do desempenho físico (Almeida,Sangiovanni, Liberali, 2009 p.201).

Existem três teorias que tentam explicar o efeito ergogênico da cafeína durante o exercício físico. A primeira seria o efeito direto no SNC. A segunda seria o efeito direto da cafeína sobre o músculo esquelético. A terceira diz respeito ao aumento na oxidação das gorduras e redução de carboidratos. (SPRIET, 1995; ALTIMARI et al, 2005; MELLO et al, 2007).

\section{DOR}

Dor é definida como "uma experiência sensorial e emocional integrada ou não a uma lesão real"' (SILVA E FILHO, 2001).

A dor ainda esta dividida ainda em dor experimental que seria a parte que não afeta o emocional do individuo ela não gera um sofrimento real e ela pode durar apenas segundos,minutos ou sessões ao contrario da Dor Clinica que é a dor provocada em laboratório e que pode durante anos esta por sua vez é que chama atenção de pesquisadores (EDWARDS RR et al., 2005).

Para Pimenta e Teixeira (2000) é uma experiência subjetiva e pessoal,tanto em termos fisiológicos quanto psicológicos.

Conceitos e fenômenos de natureza subjetiva, como a dor, são difíceis de serem mensurados perfeitamente, ou seja, quantificados por meio de instrumentos e processos isentos de erros sistemáticos. Sua percepção é multifacetada portando é cognitiva, sensorial e motivacional.

A cognitiva esta ligada a compreensão de experiências dolorosas em que o 


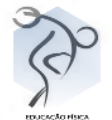

individuo possa ter vivido a sensorial esta ligado diretamente com aspectos físicos da dor e por fim a dor motivacional esta ligada como o individuo interpreta a experiência dolorosa que podem envolver sentimentos como medo e tensões pré-determinadas, (PIMENTA, 1999)

A Percepção de esforço (PE), segundo Borg (2000), está ligada ao trabalho muscular intenso em que envolve tanto o sistema musculoesquelético quanto o cardiorrespiratório. Ainda, a PE está ligada a intensidade do exercício, podendo ser pautada como PSE, desconforto e/ou fadiga que são aparentes durante os exercícios.

Borg (2000, p.21)ainda relata que, "medida de esforço percebido é o grau de peso e tensão vivenciados durante o trabalho físico e estimado de acordo com um método classificatório específico".

Sabemos que em muitos estudos existem evidências que a percepção de dor é um possível limitante do desempenho (O’CONNOR e COOK, 1999).

Nos estudos de Cook et al. (1997), comprovam que durante os exercícios aeróbios as sensações de esforço e dor são definitivos pra o desempenho físico.

Astorino et al (2011) observaram que a ingestão de cafeína apresentou resultados parecidos de percepção de dor, com isto podendo observar a melhora do desempenho físico e ainda que existe a diminuição da percepção de dor pode ser atribuída a aspectos periféricos e centrais.

Assim, como Smirmaul (2010) propõe que os mecanismos responsáveis pela percepção de dor integram áreas cerebrais ligadas ao comportamento e às emoções. A dor atua não somente como uma resposta a determinado estímulo, mas também como um agente modificador de comportamento. É possível concluir que a percepção de dor é parte do controle homeostático do corpo humano, e pode agir como um meio de melhorar decisões comportamentais durante o exercício físico, baseado no feedback aferente sensorial.

\subsection{Fadiga Muscular}

Para um bom resultado em suas modalidades esportivas atletas devem manter ações musculares repetidas por períodos prolongados na literatura essas ações são os resultados de uma serie de eventos fisiológicos, e a incapacidade desses eventos é definida 


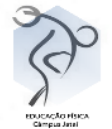

como fadiga (EDWARDS, 1983).

Portanto a fadiga muscular é estudada constantemente na fisiologia do exercício devido à necessidade de melhorar o rendimento do atleta (ASCENSÃO et al., 2003).

De acordo com Enoka e Stuart, (1992) o sistema neuromuscular tem propriedade adaptativa rápida, portanto, de acordo com o que o organismo necessita e a forma que é estimulado, ele mantém os níveis necessários para que as estruturas do músculo esquelético possam gerar a força necessária pra manter-se em equilíbrio, caso este equilíbrio seja afetado corre uma fadiga neuromuscular.

Portanto a fadiga muscular é definida pela redução em que o sistema muscular perde a capacidade de gerar força suficiente pra sua manutenção (WOLEDGE, 1998).

Mas também encontrou-se na literatura que alguns autores têm associado o termo "fadiga" como a incapacidade funcional do organismo durante exercícios por incapacidades funcionais (ASCENSÃO et al., 2003).

Mas devido a sua complexidade a fadiga pode ser classificada em fadiga muscular localizada, que podemos caracteriza-la como o declínio do desempenho durante o exercício. Frequentemente, essa degradação do desempenho mecânico é o parâmetro utilizado por especialistas para definir o "ponto de fadiga" o qual o músculo não é mais capaz de sustentar seu nível de força desejado para realização da tarefa.

A fadiga aguda por sua vez pode ter origem em um ou em todos os sistemas fisiológicos envolvidos na ação muscular, desde o SNC até as estruturas contráteis (DAVIS E BAILEY, 1997).

Existe também a hipótese que relaciona a fadiga muscular aguda com o sistema cardiorrespiratório, ela ocorre devido à condução baixa de oxigênio aos grupos musculares (BASSET; HOWLEY, 1997).

\section{MÉTODO}

Trata-se de uma revisão sistemática. A pesquisa foi realizada nas bases de dados Scielo, Bireme e Pudmed e para busca, foram utilizados os seguintes termos/descritores em Ciências da Saúde, na língua portuguesa: "cafeína", "recurso ergogênico", "exercício físico", 


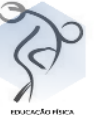

"fadiga muscular" e "dor". Na língua inglesa: "caffeine", "ergogenic aid", "muscle fatigue", "physical exercise" and "pain perception"

Para tal, foram considerados os seguintes critérios de inclusão: Artigos de metaanálise, revisão sistemática, revisão de literatura.

Dos estudos selecionados foram analisados os seguintes aspectos para critérios de inclusão na pesquisa: a) utilização da cafeína como recurso ergogênico; b) cafeína como redutor da fadiga muscular; c) cafeína e percepção de dor (PSE); d) mecanismo de ação da cafeína no organismo.

A seleção dos estudos foi realizada, em três etapas: $1^{\circ}$ etapa - leitura dos títulos; $2^{\circ}$ etapa - leitura dos resumos dos artigos selecionados na $1^{\mathrm{a}}$ etapa; $3^{\circ}$ etapa - leitura na íntegra dos artigos selecionados na $2^{\mathrm{a}}$ etapa.

\section{RESULTADOS E DISCUSSÃO}

Dos 362 artigos obtidos na busca inicial, 183 deles foram selecionados após a leitura dos títulos ( $1^{\mathrm{a}}$ etapa) e, dentre estes, 149 foram excluídos após a leitura dos resumos ( $2^{\mathrm{a}}$ etapa), já que não atendiam integralmente aos critérios de inclusão. Permaneceram, portanto, para leitura na íntegra ( $3^{\text {a }}$ etapa), 34 artigos, dentre os quais, excluiu-se 4 artigos, que estavam em desacordo com os critérios de inclusão.

Ao final, foi alcançando o total de 30 trabalhos, o que apenas 1 artigo relatou os efeitos da ingestão da cafeína e o processo do limiar de esforço percebido (LEP) e 2 que trataram especificamente da cafeína no retardo da fadiga e melhora da performance.

O processo de seleção dos artigos é apresentado na Figura 1. E os 3 artigos específicos no quadro 1.

Figura 1: Processo de seleção dos artigos publicados sobre os efeitos da cafeína e redução da fadiga e dor durante o exercício.

362 Artigos encontrados

Nas Bases de dados
10 fase

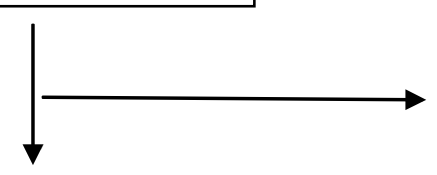

179 Artigos excluídos após a leitura do Titulo Pois eram estudos realizados com animais 


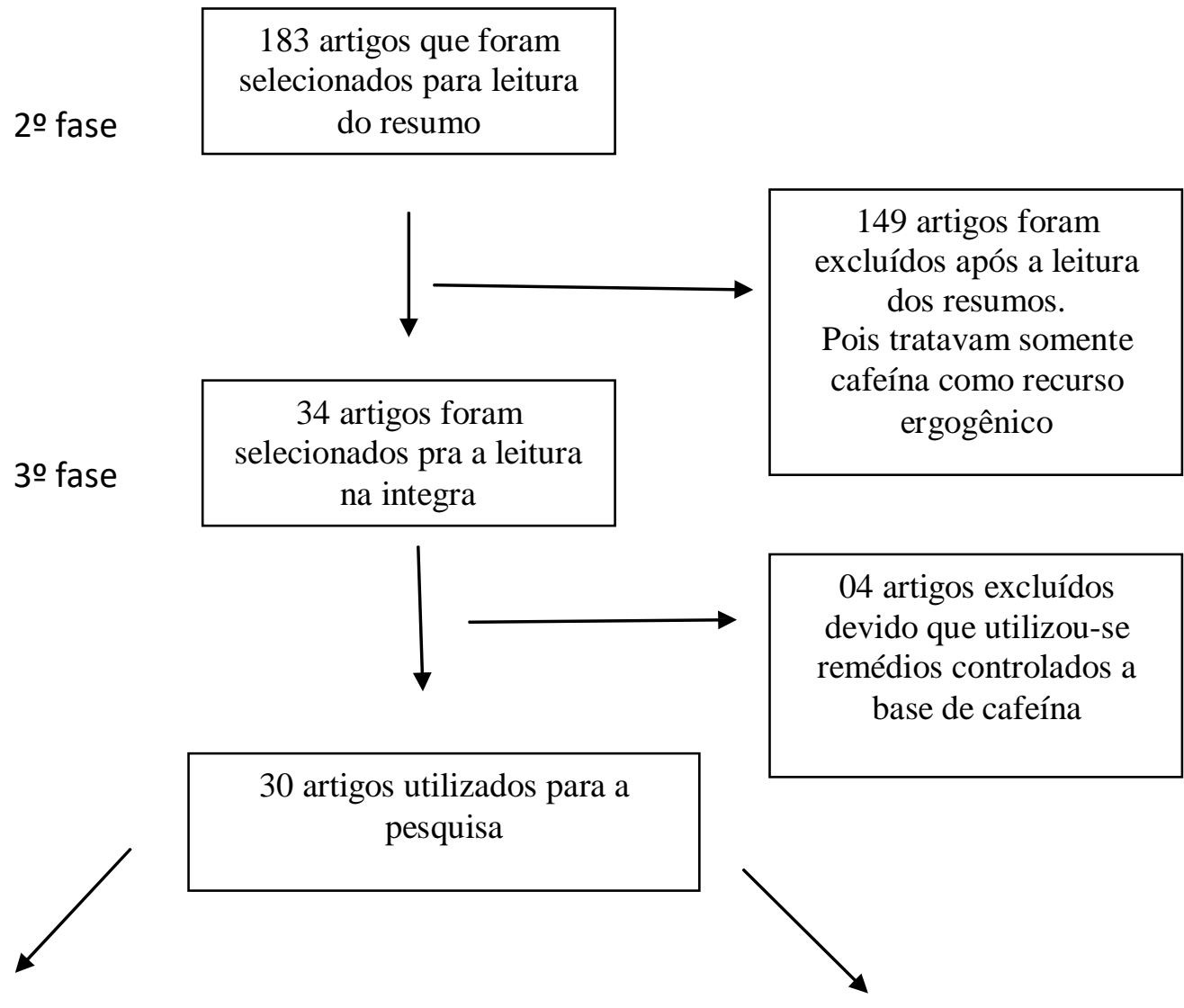

Um artigo retratou

Os efeitos da ingestão da

cafeína e o processo do

limiar de esforço percebido

(LEP)

Dois artigos retrataram especificamente da cafeína no retardo da fadiga e melhora da performance.

Fonte: OLIVEIRA et al 2019

Quadro 1: Artigos que retrataram especificamente e tema proposto na revisão sistemática

\begin{tabular}{|l|l|l|c|}
\hline Autores & Ano & Titulo & Conclusão \\
\hline ALTIMARI et al & 2008 & A influencia da ingestão & Ingestão de \\
& & de CAF sobre a FNM e o & $6 \mathrm{mg} / \mathrm{kg}$ de
\end{tabular}




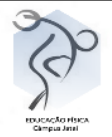

\begin{tabular}{|c|c|c|c|}
\hline & & $\begin{array}{c}\text { desempenho físico } \\
\text { durante exercício supra- } \\
\text { Maximo }\end{array}$ & $\begin{array}{c}\text { cafeína aumenta } \\
\text { o tempo para } \\
\text { inicio da fadiga } \\
\text { neuromuscular }\end{array}$ \\
\hline TRIANA et al & 2009 & $\begin{array}{l}\text { Verificar o efeito agudo } \\
\text { da ingestão da cafeína } \\
\text { sobre o LEP }\end{array}$ & $\begin{array}{l}\text { Conclui que o } \\
\text { LEP não foi } \\
\text { alterado, mas } \\
\text { demonstrou ser } \\
\text { eficaz para } \\
\text { prolongar o } \\
\text { tempo de } \\
\text { exaustão. }\end{array}$ \\
\hline RIBAS & 2010 & $\begin{array}{l}\text { Revisão: Cafeína para o } \\
\text { retardo da fadiga e para a } \\
\text { melhora da } \\
\text { performance,comparando } \\
\text { Doses, protocolos e tipos } \\
\text { de exercícios. }\end{array}$ & $\begin{array}{c}\text { Efeitos } \\
\text { permitem a } \\
\text { diminuição da } \\
\text { sensação de } \\
\text { fadiga e dessa } \\
\text { forma } \\
\text { prolongando a } \\
\text { execução do } \\
\text { exercício físico. }\end{array}$ \\
\hline
\end{tabular}

Fonte: OLIVEIRA et al 2019

Observou- se na presente revisão que o estudo de Altimari et al (2001), analisaram a cafeína como ergogênico nutricional no esporte acreditam que ela tenha mecanismos com ações centrais e periféricas assim sendo capaz de desencadear importantes funções fisiológicas e metabólicas no organismo que por sua vez são capazes de aprimorar a performance dos atletas.

Por outro lado neste estudo foi contraditório aos achados mais recentes, pois nele traz seus resultados em relação ao aumento das capacidades físicas principalmente em 


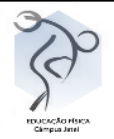

exercícios menos intensos.

Embora para Altimari et al (2008) estudo o qual, tratou especificamente a ingestão da cafeína e o aumento do tempo de fadiga neuromuscular em ciclistas em exercício supramáximo,seus achados nos revela que a utilização da cafeína em exercício de curta duração supramáximo pode melhorar o desempenho e diminuir a fadiga neuromuscular.Devido a propagação dos sinais agirem diretamente no sistema neural,bem como no músculo esquelético DAVIS et al(,2003).

Foram encontrados na literatura, trabalhos utilização da Eletromiografia em exercícios isométricos o qual foi encontrado aumento significativo ao tempo de exaustão e redução na percepção da força muscular.(WALTON et al 2002).

Fox e Mathews ( ), concluíram que a cafeína poupa glicogênio durante o exercício assim utilizando dos lípides como substrato energético para a contração muscular e desse modo a redução da fadiga muscular, com isto um aumento da performance do atleta.

Podemos então concluir a respeito da cafeína como ergogênico na atividade física, segundo Farias et al (2013), que embora encontrassem disponíveis na literatura estudos dos efeitos ergogênicos da cafeína sobre o desempenho físico, nos exercícios aeróbios está bem documentado, porém, durante exercícios anaeróbios, a maioria dos estudos não concluíram quais os efeitos da cafeína no metabolismo anaeróbio.

Dentre os achados os resultados para artigos relacionando a cafeína com a redução da fadiga muscular, demonstram estruturas semelhantes da adenosina e cafeína , assim a cafeína inibir o efeito da adenosina, permitindo a excitabilidade neuronal e assim estimulando sistema nervoso central e cardíaco e ainda estimulando um aumento da adrenalina. (GRAHAM,2001;PEREIRA et al,2010)

Em relação à dose e consumo segundo Bell e Mclellan,( 2002) existe estímulos diferentes para consumidores e não consumidores de cafeína.

Em um estudo sobre o efeito da dose de cafeína na redução da percepção da dor no músculo da perna durante um exercício de ciclismo (60\% VO2), pode identificar que uma dose de $10 \mathrm{mg} / \mathrm{Kg}$ de cafeína 60 minutos antes do exercício físico, provocou uma diminuição na intensidade da dor no quadríceps, já no grupo que ingeriu $5 \mathrm{mg} / \mathrm{Kg}$ ou placebo identificou que o tempo de resposta pra dor foi menor do que o grupo anterior, sugerindo então que a 




cafeína poderia ter atuado em receptores de adenosina ligados à dor. Por não haver uma diferença grande na resposta para as doses de 10 e $5 \mathrm{mg}$, foi indicado que isso tenha ocorrido devido o baixo grau de treinamento dos participantes (O’Connor et al, 2004).

Laurent et al (2000) observaram em estudo com ciclistas os quais ingeriram 6mg/Kg de cafeína 90 minutos antes do teste, não encontrou diminuição na taxa do glicogênio muscular em comparação ao grupo placebo, apenas uma maior liberação de endorfinas responsáveis pelo aumento do tempo de teste.

Em compensação, Greer e Colaboradores (2000), testaram sete ciclistas pedalando e que relataram uma economia do uso do glicogênio muscular com a suplementação de cafeína $(6 \mathrm{mg} / \mathrm{kg})$.

Da mesma forma, estudo de Silveira et al (2004), em ciclistas pedalando de forma intensa e intermitente, resultou num maior tempo até a exaustão.

A cafeína aumenta a oxidação de lipídios com isto e por esse motivo, acreditamos que sua utilização seja responsável pelo aumento da performance atlética.(IVY Apud Granham 2001).

Por diminuir a sensação de fadiga durante o exercício, a cafeína consequentemente altera a percepção da dor. Ainda em seu estudo encontraram em jogadores de rúgbi um melhor desempenho e menor fadiga (ROBERTS et al 2010) .

Quando combinada cafeína com analgésicos e anti-inflamatórios, a cafeína pode contribuir com a melhora da dor, promovendo de certa forma, um maior desempenho nos exercícios, por ser capaz de potencializar o efeito do medicamento (GRAHAM, 2001).

Em relação à Percepção Subjetiva de Esforço (PSE) e a ação da cafeína para sua diminuição durante o exercício físico seria favorecido através da manutenção da motivação do atleta, pois é uma relação pessoal e de difícil controle externo, uma vez que tanto os neurotransmissores e neuromoduladores e o humor individual do atleta, conclui-se que a percepção de esforço instiga a continuidade do exercício. (GANDEVIA, 2001, NYBO; SECHER, 2004).

Dentre os 30 artigos analisados apenas três deles analisaram de fato os objetivos deste trabalho uma vez que (ALTIMARI et al 2008,TRIANA,2009 e RIBAS,2010)trataram separadamente,fadiga como redutora da fadiga neuromuscular, cafeína como efeitos no limiar 


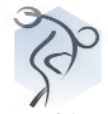

da dor e melhora da performance física.

Resultados sobre os efeitos da Cafeína na Redução da fadiga Muscular e Dor Durante o Exercício foram encontrados na analise dos estudos encontrados separadamente, devido a diferentes variáveis de ações fisiológicas e psicofisiológicas dos mecanismos de ações da cafeína no organismo humano. Contudo houve achados específicos de que existe a atuação da cafeína como um potente ergogênico nas principais funções do SNC e sua atuação dos demais sistemas, com isto concluindo que existe uma redução da fadiga neuromuscular e na percepção da dor durante o exercício.

O fato da busca ter sido realizada em poucas bases de dados constitui uma limitação do presente estudo, com isto pode inviabilizar a obtenção de publicações em periódicos não indexados nessas bases, podendo subestimar a quantidade de estudos com a temática da Cafeína na Redução da Fadiga e Dor. Entretanto, essa revisão sistemática utilizou os últimos estudos referentes á cafeína na redução da fadiga e dor durante o exercício em uma das principais bases científicas internacionais com cerca de 22 milhões de artigos biomédicos publicados até o momento.

\section{CONCLUSÃO}

Após a presente revisão sistemática encontrou -se efeitos da cafeína na redução da fadiga e dor durante o exercício, nos seguintes aspectos: ela atua no Sistema Nervoso Central, sistema cardiovascular e nos níveis de eletrólitos.

Dentre esses aspectos sabemos que a atuação da cafeína sobre o Sistema Nervoso Central SNC, é onde ocorre seu principal efeito assim agindo diretamente como estimulante, pois age de forma antagonista aos receptores de adenosina dessa forma aumenta a função neural, associando as estruturas de contração muscular e assim diminuindo a fadiga muscular.

Do mesmo modo em relação às participantes das pesquisas eram homens já treinados e/ou pessoa que não consumidores de cafeína, o que pode-se concluir que a cafeína teve um bom resultado em atletas, pois já estão adaptados ao treinamento com isso o estimulo ergogênico utilizado atenua a dor e fadiga e assim aumenta sua performance,já o não consumidor da cafeína devido ao não consumo quando utilizado o organismo e as respostas 


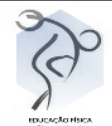

fisiológicas do SNC são benéficas se a quantidade ingerida estiver de acordo com o padrão.

Recomenda-se então que mais estudos sejam realizados, comparando experimentalmente os efeitos e as variáveis que a cafeína pode atingir em indivíduos comuns e se estes efeitos podem ou não ser benéficos para suas atividades diárias.

\section{REFERÊNCIAS}

ALMEIDA,C.;SANGIOVANNI,D.;LIBERALI,R.Cafeína:Efeitos ergogênicos nos exercícios físicos.Revista Brasileira de Nutrição Esportiva. São Paulo.v.3.n.15.p198-209.2009.

ALTIMARI, L.R.; CYRINO, E.S.; ZUCAS, S.M.; BURINI, R.C. D. Efeitos Ergogênicos da Cafeína Sobre o Desempenho Físico. REVISTA PAULISTA DE EDUCAÇÃO FÍSICA. São Paulo. V.2. n.14. p. 141 - 58.2000.

ALTIMARI,L.R, et al. Cafeína:ergogênico nutricional no esporte Brazilian.Jornaus.Sci.Moviment,v.9,n.3,p.57-64,2001.

ALTIMARI, L.R.; MELO, J. ; TRINDADE, M.; TIRAPEGUI, J. E. Efeito Ergogênico da Cafeína na Performance em Exercícios de Média e Longa Duração. Revista Portuguesa de Ciências do Desporto. v.5. n.1. p. 87 - 101.2005.

ALTIMARI, L. R.; MORAES, A. C.; TIRAPEGUI,J.; MOREAU, R. L. M. Cafeína e performance em exercícios anaeróbios. Revista Brasileira de Ciências Farmacêuticas = Brazilian Journal of harmaceutical Sciences, São Paulo, v.42, n.1, p.17-27, 2006. Disponível em: $>$ http://www.rbcf.usp.br/Edicoes/Volumes/v42n1/P $<$. Acesso em: 31 jan. 2016.

ALTIMARI, L.R.; FONTE, E.B.; OKANO, A.H.; TRIANA, R.O.; Chacon- MIKAHIL, M.P.T.; MORAES, A.C. A Ingestão de Cafeína Aumenta o Tempo para Fadiga Neuromuscular e o Desempenho Físico Durante Exercício Supramáximo no Ciclismo. Brazilian Journal of Biomotricity. v.2. n.3. p.195 - 203.2008.

ASCENSÃO A, MAGALHÃES J, OLIVEIRA J, DUARTE J, SOARES J. "Fisiologia da fadiga muscular. Delimitação conceptual, modelos de estudo e mecanismos de fadiga de origem central e periférica”. Revista Porto Ciências Desporto. 2003.

ASTORINO,T.A.;TERZI M.N,; ROBERSO,D.W.;BURMETT,T.R.; Effect of caffeine intake on pain perception during high-intensity exercise. Int J Sport Nutr Exerc Metab .v.21.n.1.p.27-32.2011.

BASSET,D.R.; HOWLEY,E.T.; Mximum oxygen uptake: "classical Versus Contemporany"view points.Medicine and Science in Sports and Exercise,Madison,v.29,n.5,p.591-603.1997. 


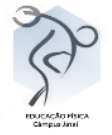

BELL, D. G., \& MCLELLAN, T. M. . Exercise endurance 1, 3, and 6 h after caffeine ingestion in caffeine users and nonusers. Journal of Applied Physiology, p.1227-1234.1993.

BORG, G. Escala de Borg para dor e esforço percebido. São Paulo: Manole: 2000.

BRAGA,L.C.; ALVES,M.P. A Cafeína como Recurso Ergogênico nos Exercícios de Endurance. Revista Brasileira de Ciências e do Movimento. Brasília v.8 n.3 p. 33-37.2000.

BERTAZZONI, C.G. Cafeína na Melhora do Desempenho em Exercícios Anaeróbios. Trabalho ( Especialização Ciências aplicadas) Escola Paulista de Medicina: São Paulo. Universidade Federal de São Paulo 2007.

CLARK, N. Guia de Nutrição Desportiva: Alimentação para uma Vida Ativa. $3^{\circ}$ ed. Porto Alegre: Artmed, 2006.

CAZÉ,R.F.; FRANCA,G.A.M.; PORPINO,S.K.P.; SOUZA,A.A.; PADILHAS,O.P.; SILVA, A.S. Influência da Cafeína na Resposta Pressórica ao Exercício Aeróbio em Sujeitos Hipertensos. Rev Bras Med Esporte. V.16. n.5.p. 324-28,2010.

COOK,D.B.;O’CONNOR,P.J.EUBANKS,S.A;SMITH,J.C.;LEE,M.Naturall y occurring muscle pain during exercise:assessment and experimental evidence.Med.Sci.Sports Exercise.v.29.p.990- 1012.1997.

DANTAS, E.H.M. A Prática da preparação física. $5^{\circ}$ ed. Rio de Janeiro: Shape, 2003.

DAVIS, J.M.; ZHAO, Z.; STOCK, H.S.; MEHL, K.A.; BUGGY, J.; HAND, G.A. Central Nervous System Effects of Caffeine and Adenosine on Fatigue. American Journal of Physiology Regulatory Integrative and Comparative Physiology. V.284. p.399 404.2003.

DAVIS, J.M.; BAILEY, S.P. "Possible mechanisms of central nervous system fatigue during exercise". Medicine and Science in Sports and Exercise,v.29.p. 45-57.1997.

De MARIA,C.A.B; MOREIRA, R.F.A. Cafeína: revisão sobre métodos de análise. Química Nova. São Paulo. V.30.n.1.p.99-105.2007.

DEL COSO, J.; MUNOZ, G.; MUNOZ-GUERRA, J. Prevalence of caffeine use in elite athletes following its removal from the World Anti-Doping Agency list of banned substances. Appl Physiol Nutr Metab.;v.36 n.4.p.555-61.2011.

DUNCAN,M.J;OXFORD,S.W. The effects of caffeine ingestion on mood state and bench press perfomance tofailure.Journal of Strength and Conditioning

Reseach,Champaign,v.25,n.1,p.178-185.2011. 


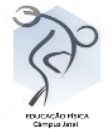

EDWARDS,R.H.T.Biochemical bases of fatigue in exercise performance:catastrophe theory of muscular fatigue.In: edited by H.G.KUNUTTGEN.Biochemistry of exercise.champion,UL:Human kinetes .p.3-8.1983.

EDWARDS, RR;Sarlani E, WESSELMANN U, et al. Quantitative assessment of experimental pain perception: multiple domains of clinical relevance. Pain.v. 3, p.114.2005.

ENOKA.R.;STUART,D.Neurobiology of muscle fadigue.J Apll Physiol,v.72.p.1631-1648.1992.

ESCOHOTADO,A. A Brief History of drugi.From the Stone Age to the Stoned Age.Vermont:Park Street Press.1999.

FREDHOLM,B.B. et al.Action of Caffeine in the brain with special reference to factors that contribute to its widespread .Pharmacological Reviews Battimore,v.51,n.1,p.83-133.1999.

FERREIRA.G.M.H.;GUERRA,G.C.B.;GERRA,R.O.Efeitos da cafeína na Percepção de esforço,temperatura,peso corporal e frequência cardíaca de ciclistas sob condição de stress térmico.Rev Brasileira de Ciências e Movimento. v.14.n.1.p.33-40.2006. GRAHAM,T.E. Caffeine and Exercise: Metabolism, Endurance and Performance. Sports Med. v.1.n.11.p.785-807, 2001.

GRAHAM, T.E., Caffeine and exercise: metabolism, endurance and performance. Sports Med. v. 31. n. 11. p. 785-807.2001.

GRAHAM, T.E. Caffeine and exercise: metabolism,endurance and performance. Sports Med., v.31, n.11, p.785-807, 2001a.

GRAHAM, T.E. Caffeine, coffee and ephedrine: impact on exercise performance and metabolism. Can. J. Appl Physiol., v.26, n.1 (Suppl), p.103S-119S, 2001 b.

HUNTER AM, GIBSON AC, COLLINS M, LAMBERT M, NOAKES TD. Caffeine ingestion does not alter performance during a 100-km cycling time-trial performance. Int $\mathbf{J}$ Sport Nutr Exerc Metab. v12.n.4.p. 438- 452, 2002.

KALMAR,J.M.; CAFARELLI, E. Caffeine: a valuable tool to study central fatigue in humans? Exercise and Sport Science Reviews. v. 32. N. 4. p. 143-147.2004.

LEITÃO,H.A.;et al. Efeitos ergogênico da cafeína sobre o desempenho físico progressivo máximo em ciclistas.Braziliam Journal of Heath.v.1.n.2.p.110-112.2010. 


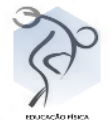

MELLO, D.; KUNZLER, D.K.; FARAH, M. Cafeína e seu efeito ergogênico. Revista Brasileira de Nutrição Esportiva. São Paulo v.1, n.2 p. 30-37, 2007.

MONTEIRO, A.G. Treinamento Personalizado: Uma abordagem didático metodológica. São Paulo: Phorte Editora. p.7-12. 2000.

PIMENTA, C. I. Fundamentos teóricos da dor e de sua avaliação. In: CARVALHO, M. M. J. (Org). Dor: um estudo multidisciplinar. São Paulo: Summus, 1999. p. 31-46.

SILVA, M, S. Os efeitos da cafeína relacionados à atividade física: uma revisão. Revista Digital - Buenos Aires - Ano 9 n66, 2003.

SMIRMAUL, B.P.C. Percepção de esforço e dor durante o exercício: Mecanismos e limitação do desempenho. 2010. 32f. Trabalho de Conclusão de Curso (Graduação)Faculdade de Educação Física. Universidade Estadual de Campinas, Campinas, 2010.

MAHDNEY, C.R. et al.Caffeine induced physiological arousal accetuates global processing bases.Pharmacology,Biochemistry and Behavior,Phoenix,v.99,p59-65. 2011.

MAUGHAN,R.I.;KING,D.S.;LEA,T. Dietary supplements. Sports Sci.,v.22,n.1,p.95$113,2014$.

O'CONNOR,P.J.;COOK,D.B.Exercise and pain:the neurobiology,measurement and laboratory study of pain in relation to exercise in humans.Exerc.Sci.Rev.v.27.p.119166.1999.

PALUSKA, S.A. Caffeine and exercise. Curr. Sports Med. Rep., v.2, n.4, p.213-219, 2003.

PLASKETT CJ.; CAFARELLI,E. Caffeine increases endurance and attenuates force sensations during submaximal isometric contractions.J Appl Physiol.v.91.n.4.p.1535$44,2011$.

PLASKETT, C.J.; CAFARELLI, E. Caffeine increases endurance and attenuates force sensation during submaximal isometric contractions. J. Appl. Physiol., v.91, n.4, p.15351544, 2001.

PEREIRA,L.A.;CYRINO,E.S.AVELAR,A.;SEGANTIN,A.Q.;ALTIMARIl, J.M.;TRINDADE,M.C.C.;ALTIMARI,L.R.A Ingestão de Cafeína não Melhora o Desempenho de atletas de Judô.Revista de Educação Física.Unesp.v.16.n.3.p.714-722.2010.

RIBEIRO,J.A.;SEBASTIÃO,AM.;MENDONÇA,A. Adenosine receptors in the nervous sydtem: pathophygiological implications.Proress in Neurobiology.Nova Iorque,v.68,n.6,p.377-392.2002. 


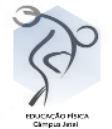

RIBAS,S.F.Cafeína no retardo da fadiga e melhora da performance. Revista Brasileira de Nutrição Esportiva, São Paulo. v. 5. n. 28. p. 285-297. ISSN 1981-9927.2010.

SPRIET, L.S. Caffeine and performance. Int. J. Sports Nutr., v.5, n.1(suppl), p.S84-99, 1995.

SOARE,M.S.J.A.;FONSECA,R.M.B.Caféina,Trabalho de Toxicologia e Analises Toxicológicas do Laboratório de Toxicologia da Faculdade de Farmácia da Universidade do Porto.2004.

SILVEIRA, L.R.; ALVES, A.A.; DENADAI, B.S. Efeito da lipólise induzida pela cafeína na performance e no metabolismo de glicose durante o exercício intermitente. Rev. Bras. Cie. e Mov. v. 12. n 3. p. 21-26.2004.

SNYDER, S. H.; SKLAR, P. Behavioral and molecular actions of caffeine: focus on adenosine. Journal of Psychiatry Research, Oxford, v. 18, n. 2, p. 91-106. 1984.

TRIANA, R.O. et al. Efeito da ingestão de cafeína sobre o limiar de esforço percebido (LEP). Motriz, Rio Claro. v. 14. n. 3. p. 300-309.2008.

WADA. World Anti Doping Agency. The 2004 prohibited list international standard. Disponível em: > http://www.wadaama< Acesso em: 11 dezembro 2015.

WALTON, C.; KALMAR, J.M.; CAFARELLI, E. Effect of caffeine on self- sustained firing in human motor units. J. Physiol., v.545, n.2, p.671-679, 2002.

WILLAMS, H. Nutrição para a saúde, condicionamento físico e desempenho esportivo. São Paulo: Manole.2002

WOOLF K, BIDWELL WK, CARLSON AG. The effect of caffeine as an ergogenic aid in anaerobic exercise. Int J Sport Nutr Exerc Metab. v 18.n.4.p. 412-429, 2008.

WOLEDGE RC. (1998), "Possible effects of fatigue on muscle efficiency" Acta Physiol Scand ,162:267-73. 